\title{
MID-YEAR STATUS REPORT FOR TTP \#SR-1320-02 UST: Cs EXTRACTION TESTING (U)
}

by

J. P. Bibler

Westinghouse Savannah River Company

Savannah River Site

Aiken, South Carolina 29808

This paper was prepared in connection with work done under the above contract number with the U. S.

Department of Energy. By acceptance of this paper, the publisher and/or recipient acknowledges the U. S.

Government's right to retain a nonexclusive, royalty-free license in and to any copyright covering this paper, along with the right to reproduce and to authorize others to reproduce all or part of the copyrighted paper. 


\section{DISCLAIMER}

This report was prepared as an account of work sponsored by an agency of the United States Government. Neither the United States Government nor any agency thereof, nor any of their employees, makes any warranty, express or implied, or assumes any legal liability or responsibility for the accuracy, completeness, or usefulness of any information, apparatus, product, or process disclosed, or represents that its use would not iniringe privately owned rights. Reference herein to any specific commercial product, process, or service by trade name, trademark, manufacturer, or otherwise does not necessarily constitute or imply its endorsement, recommendation, or favoring by the United States Government or any agency thereof. The views and opinions of authors expressed herein do not necessarily state or reflect those of the United States Government or any agency thereof.

This report has been reproduced directly from the best available copy.

Available to DOE and DOE contractors from the Office of Scientific and Technical Information, P. O. Box 62, Oak Ridge, TN 37831; prices available from (615) 576-8401.

Available to the public from the National Technical Information Service, U. S. Department of Commerce, 5285 Port Royal Rd., Springfield, VA 22161 
SAVANNAH RIVER TECHNOLOGY CENTER

INTERIM WASTE TECHNOLOGY
WSRC-RP-93-610

Key Words: Ion Exchange, Cesium Decontamination, Radiation, Supernate

April 29, 1993

TO: S.D. FINK, 773-A

FROM: J.P. BIBLER, 773-A G/B

MID-YEAR STATUS REPORT FOR TTP \# SR-1320-02

\section{UST: Cs EXTRACTION TESTING}

\subsection{SUMMARY}

The resorcinol/formaldehyde resin developed at WSRC (Westinghouse Savannah River Company) has been studied with simulated Hanford 242-101-AW (HW) liquid waste. In the course of these studies new properties of the resin have been identified. Pertinent findings from these studies include:

- Studies in which HW was processed at increasingly greater flow rates on a two-milliliter column of resin that had been pretreated in $2 \mathrm{M} \mathrm{NaOH}$ showed that $\mathrm{Cs}^{+}$ion was not efficiently sorbed by the resin. Increasing the flow rate decreased the number of column volumes that could be processed before breakthrough occurred. Data from these experiments indicated that this feed would be difficult to decontaminate using this resin. The sorption of $\mathrm{Cs}^{+}$ from the simulant appeared to be limited by diffusion of the ion to the resin.

- Pretreating the resin with $6 \mathrm{M} \mathrm{NaOH}$ increased swelling of the resin in a manner similar to the swelling observed in HW. A $2-\mathrm{mL}$ column pretreated with the more concentrated caustic was used to decontaminate $450 \mathrm{~mL}$ of $\mathrm{HW}$ at a flow rate of five column volumes per hour. Apparently, proper pretreatment of the resin allows efficient cesium decontamination from this waste simulant at reasonable flow rates.

- The breakthrough curve for the column pretreated with $6 \mathrm{M} \mathrm{NaOH}$ showed a distinct, sharp breakthrough at 225 column volumes throughput and a second less well defined breakthrough at 450 column volumes. This indicates that the second hydroxide functional group was participating in ion exchange, effectively doubling the capacity of the resin. Activation of the second hydroxide had never before been observed. Elution of the spent resin was accomplished in 47.5 column volumes of $0.1 \mathrm{M} \mathrm{HNO} 3$.

- Radiolysis studies in the $1 \mathrm{E}+8$ rad dose region show no significant change in the resin cesium distribution constants $(\mathrm{Kd})$ with increasing dose when the resin is irradiated in deionized water.

- Researchers working with the resorcinol/formaldehyde resin at WSRC, Oak Ridge (ORNL), and PNL (Pacific Northwest Laboratories) have all experienced a degradation of the resin with time. It was determined at a 
meeting of the researchers that the resin has a shelf life, probably less than its process life, that is determined by oxidation of the resin. A program was outlined to determine the shelf life, storage requirements, and mechanism of degradation of the resin. Oxidation is suspected as the chemical process of degradation.

- Because all of the resin being used at this time in the DOE (Department of Energy) complex is from one production batch and, because it is displaying decreasing ion exchange performance with time, a recommendation to purchase a new batch of resin from a vendor has been made. This will generate a uniform supply of resin for all researchers and will demonstrate once again that quality resincan be commercially made in acceptable quantity.

\subsection{INTRODUCTION}

This project was designed to perform several tasks to provide transfer of technology to PNL concerning optimization of a cesium-specific ion exchange resin, developed at WSRC. The tasks support the development of a Compact Processing Unit (CPU) for Csremoval from a variety of waste streams at Westinghouse Hanford (WH).

In a series of experiments, WSRC has studied the behavior of a small column of the resin at various, increasingly greater flow rates with the HW simulant solution to determine an optimum column loading rate. Elution studies of the resin after saturation with $\mathrm{Cs}^{+}$will generate an elution profile from which an optimum elution medium, flow rate, and volume can be determined. Small column tests at temperatures ranging from $40^{\circ} \mathrm{C}$ $80^{\circ} \mathrm{C}$ are planned but have not yet begun.

Further, WSRC has begun a study in which the resin is subjected to ionizing radiation in a Co-60 source. This study will determine if any flammable or hazardous compounds, that might require special process controls, are formed as a result of irradiation. it will also define the ability of the resin to maintain its selectivity and capacity in a radiation field. During this period, a literature survey of the effects of radiation on this type of resin and similar compounds was initiated. For this survey, the extensive database established by the Radiation Chemistry Data Center at the University of Notre Dame is being used.

\subsection{EXPERIMENTAL}

This report summarizes work accomplished to date on the project as a whole. Studies for which data is not yet available are not reported.

\subsection{Small Column Studies with Simulated Hanford 241-101-A W Waste}

A sample of resin, freshly prepared in the laboratory, was treated with excess $2 \mathrm{M} \mathrm{NaOH}$, washed with deionized water, and air-dried at room temp rature. A portion of resin treated in that manner was placed in a graduate cylinder under $2 \mathrm{M} \mathrm{NaOH}$ and allowed to stand until it had finished swelling. Resin was withdrawn from the cylinder using a dropper until $2 \mathrm{~mL}$ of resin remained. That $2 \mathrm{~mL}$ of resin was transferred with a dropper to a small ion exchange column. The column was prepared in $2 \mathrm{M} \mathrm{NaOH}$. 
Simulated Hanford 241-101-AW waste, prepared according to the composition given in Table 1 was processed downflow through the $2 \mathrm{~mL}$ column at flow rates of $30 \mathrm{~mL} / \mathrm{hr}, 20 \mathrm{~mL} / \mathrm{hr}, 15 \mathrm{~mL} / \mathrm{hr}$, and $6 \mathrm{~mL} / \mathrm{hr}(15,10,7.5$ and 3 column volume/hr). The treated effluent was collected and analyzed for Cs-137 by $\gamma-$ counting. Samples of the simulant batches were sent for analysis by $\gamma-$ counting for Cs-137, ICPES (inductively coupled plasma emission spectroscopy) for several metals, and AA (atomic absorption) for $K$. A titration was made with standard acid to determine the free $\left[\mathrm{OH}^{-}\right]$.

A 1-gram sample of resin was placed in a graduate cylinder and allowed to sweli in $6 \mathrm{M}$ $\mathrm{NaOH}$. When the swelling had stopped, the final volume occupied by the resin was recorded. This value constitutes the bulk density of the resin in $6 \mathrm{M} \mathrm{NaOH}$. A 0.72 gram sample of resin pretreated in $6 \mathrm{M} \mathrm{NaOH}(2.2 \mathrm{~mL})$ was transferred to a small column (1.1 $\mathrm{cm} \times 0.9 \mathrm{~cm}$ ) and used to treat $\mathrm{HW}$ simulant in a downflow mode at $10 \mathrm{~mL} / \mathrm{hr}$. Samples of treated effluent

from the column were analyzed for $\mathrm{Cs}-137$ by $\gamma$-counting to determine breakthrough curves. This column was stopped after 300 column volumes had been processed and was allowed to stand in simulant feed for one week before restarting. Similarly, the column stood inactive in simulant feed for two days after $325,360,400$, and 450 column volumes, and for two weeks after 500 column volumes before restarting feed operations.

Table 1. Hanford 101-AW Simulant Composition

\section{Chemical Formula}

$\mathrm{NaOH}$

$\mathrm{Al}\left(\mathrm{NO}_{3}\right)_{3} \cdot 9 \mathrm{H}_{2} \mathrm{O}$

$\mathrm{NaNO}_{3}$

$\mathrm{Na}_{2} \mathrm{CO}_{3} \cdot \mathrm{H}_{2} \mathrm{O}$

$\mathrm{Na}_{2} \mathrm{SO}_{4}$

$\mathrm{KOH}$

$\mathrm{CsNO}_{3}$

$\mathrm{NaNO}_{2}$

Cs-137

\section{g/Liter}

203

188

204

26.5

2.6

57

0.009

152

$25 \lambda$ *

\section{Molarity}

5.1

0.5

2.4

0.21

0.01

1.1

4.4 E-5

2.2

1.3 E-11

* Taken from a stock ${ }^{137} \mathrm{CsNO}_{3}$ solution (1.43 E-5 Ci/mL)

The Cs-saturated resin from the column prepared in $6 \mathrm{M} \mathrm{NaOH}$ was washed with $100 \mathrm{~mL}$ of deionized water and eluted in an upflow mode using $0.1 \mathrm{MHNO}$. The eluted material was analyzed for Cs-137 by $\gamma$-counting, for $\mathrm{Na}$ by ICPES, and for $\mathrm{K}$ by $\mathrm{AA}$.

\subsection{Batch Tests on ResorcinolVFormaldehyde Resins'}

Grab samples of resorcinol/formaldehyde resin, purchased from Boulder Scientific Co. in 1989 were taken from storage drums, converted to the $\mathrm{Na}$-form with $2 \mathrm{M} \mathrm{NaOH}$, and tested for their cesium distribution constants, Kd's, using four WSRC waste simulants (see Table 2). The procedure for determining Kd's is to shake a weighed amount of resin 
with a measured volume of solution until the system has reached equilibrium. The untreated solution and the equilibrated solution are then analyzed for cesium content. The distribution constant is calculated from the relationship in Eq. (1):

$$
\begin{aligned}
& \mathrm{Kd}=[\mathrm{Cs} \text { on resin }] /[\mathrm{Cs} \text { in solution at equilibrium }]=[(\mathrm{Co} / \mathrm{C})-1]^{*} \mathrm{~V} / \mathrm{g} \\
& \text { where } \quad \begin{array}{l}
\mathrm{Co}=\text { initial } \mathrm{Cs}^{+} \text {concentration in solution } \\
\mathrm{C}=\text { equilibrium } \mathrm{Cs}^{+} \text {concentration in solution } \\
\mathrm{V}=\text { volume, in } \mathrm{mL} \text {, of solution used } \\
\mathrm{g}=\text { grams of dry resin used }
\end{array}
\end{aligned}
$$

This same procedure was used in the radiolysis studies associated with this work, when testing resin that had been frozen and oxidized, and in testing resin that had been newlyprepared in the laboratory. Kd values obtained were compared with each other and with those already in a data base from previous work done using the resorcinol/formaldehyde resin.

Table 2. WSRC Simulated Solutions Used for Kd Tests

Solution

1

2

3

SS
Composition

4.5 M NaNO3; $1.5 \mathrm{M} \mathrm{NaOH}$; trace Cs-137

4.5 $\mathrm{M} \mathrm{NaNO}_{3} ; 1.5 \mathrm{M} \mathrm{NaOH}$; trace Cs- $137 ; 2.5 \mathrm{E}-4 \mathrm{M} \mathrm{Cs}^{+}$

4.5 M NaNO3; $1.5 \mathrm{M} \mathrm{NaOH}$; trace Cs-137; 2.5E-3M Cs ${ }^{+}$

Simulated WSRC supernate solution-2.5 E-4M Cs${ }^{+}, 2.9 \mathrm{M}$

$\mathrm{NaOH}, 0.76 \mathrm{M} \mathrm{Al}\left(\mathrm{NO}_{3}\right) 3,1.2 \mathrm{M} \mathrm{NaNO} 3,0.7 \mathrm{M} \mathrm{NaNO}$,

$0.01 \mathrm{M} \mathrm{KNO} 3,0.01 \mathrm{M} \mathrm{Na} 2 \mathrm{SO}_{4}, 0.40 \mathrm{M} \mathrm{Na}_{2} \mathrm{CrO}_{4}$

\subsection{Freezing of Resorcinolfformaldehyde Resin}

Samples taken from drums containing resorcinol/formaldehyde resin manufactured by Boulder Scientific Co. in 1989 were converted to the Na-form in $2 \mathrm{M} \mathrm{NaOH}$. Air-dried samples of the resin were placed in a freezer at $0^{\circ} \mathrm{C}$ for three-day intervals, after which they were removed and allowed to return to room temperature, $23^{\circ} \mathrm{C}$. Batch distribution constants were determined for resins, treated in this manner. This process was repeated three times for a total freeze time of 9 days.

\subsection{Exposure of Resorcinol/Formaldehyde Resin to Air}

A portion of resorcinol/formaldehyde resin from Drum 1995 was converted to he Naform using $2 \mathrm{M} \mathrm{NaOH}$. It was placed in a Büchner funnel and compressed air was delivered upflow through the resin for 1 week. At the end of that time, the Cs $\mathrm{Kd}$ 's for the resin were determined. 


\subsection{Radiolysis Studies}

\subsubsection{Irradiation Facility}

The samples were irradiated with Co-60 gamma rays at a dose rate of $2.6 \mathrm{E} 06 \mathrm{rads} / \mathrm{hour}$. The Co-60 slugs were submerged in 20 feet of water for shielding. The dose rate was determined using thin-filmed nylon dosimeters containing a radiochromic dye. ${ }^{1}$ These dosimeters were calibrated using the Fricke dosimeter 2 which is a chemical dosimeter that measures the absolute amount of radiation sorbed by a system when exposed to gamma rays.

\subsubsection{Irradiation of Samples}

The resin was irradiated as received in the Na-form. For the initial tests samples were irradiated in graduated, conical-bottomed, glass centrifuge tubes ( $15 \mathrm{~mL}$ capacity). Two $\mathrm{mI}$. of the resin were added to each tube followed by the addition of $10 \mathrm{~mL}$ of either simulated Hanford supernate or deionized water. Resin was irradiated in deionized water to aid in determining the mechanism of the radiolytic degradation. (Hanford supernate is highly caustic and contains high concentration of ions which would interfere with many of the solution analyses.) Twelve samples were prepared - six resin-supernate and six resin-water. Eight of the samples (four of each kind) were irradiated. Four (two of a kind) were retained as blanks. To decrease evaporation of water during the irradiation, the open ends of the tubes were covered with Al foil secured by a wire. Radiation times were 67.5, 162.6, and 235.2 hours giving doses of 1.6E08, 3.7E08, and 5.4E08 rads, respectively. During the irradiation, the temperature of the samples increased to $45-50^{\circ} \mathrm{C}$ due to heating by sorption of the gamma rays. Two samples (a resin-supernate and a resin-water) were removed at each of the first two doses. The remaining four samples were removed at the final dose.

\subsubsection{Analyses After Iradiation}

After irradiation, the properties of the irradiated solutions were compared to those of the unirradiated solutions. The volumes of the resins were noted along with any other visible changes. The $\mathrm{pH}$ values of the resin-water solutions were measured. The resin was collected, rinsed, and air dried. The Kd values of the unirradiated and irradiated resins were then determined and compared. The solutions from the resin/water samples were analyzed by ion chromatography for soluble anions. Samples of the solutions were submitted for aralyses of the soluble organic compounds by HPLC (High Performance Liquid Chromatography).

\subsection{Results and Discussion}

The results of analyses on HW simulants are found in Table 3 . These analyses were performed to establish the concentration of key ions in the simulant. Aluminum wa: lower than expected in each batch.

The bulk density, $\rho_{B}$, was determined to be $0.36 \mathrm{~g} / \mathrm{mL}$ in $2 \mathrm{M} \mathrm{NaOH}$ and $0.33 \mathrm{~g} / \mathrm{mL}$ in 6 $\mathrm{M} \mathrm{NaOH}$. 
S.D. FINK

WSRC-RP-93-610

April 29, 1993

Page 6

Table 3. Analytical Results for Three Batches of Hanford 241-101-AW Simulant $\mathrm{mg} / \mathrm{L}$

\begin{tabular}{|c|c|c|c|c|}
\hline Species & Estimated & Batch 1 & Batch 2 & Batch 3 \\
\hline $\begin{array}{l}\mathrm{Na} \\
\mathrm{K} \\
\mathrm{Al}\end{array}$ & $\begin{array}{l}2.53 \mathrm{E}+5 \\
4.29 \mathrm{E}+4 \\
1.35 \mathrm{E}+4\end{array}$ & $\begin{array}{l}2.24 \mathrm{E}+5 \\
3.23 \mathrm{E}+4 \\
6.40 \mathrm{E}+3\end{array}$ & $\begin{array}{l}2.14 \mathrm{E}+5 \\
3.03 \mathrm{E}+4 \\
6.67 \mathrm{E}+3\end{array}$ & $\begin{array}{l}2.28 \mathrm{E}+5 \\
3.16 \mathrm{E}+4 \\
6.58 \mathrm{E}+3\end{array}$ \\
\hline total $\mathrm{OH}^{-}$ & $1.05 E+5$ & ond & - & $9.18 \mathrm{E}+4$ \\
\hline $\begin{array}{l}\text { free } \mathrm{OH}^{-} \\
\mathrm{Al}(\mathrm{OH}) 4^{-}\end{array}$ & $8.84 E+4$ & - & - & $\begin{array}{l}8.36 \mathrm{E} \\
2.09 \mathrm{E}\end{array}$ \\
\hline
\end{tabular}

\subsection{Small Column Tests}

Resin pretreated with $2 \mathrm{M} \mathrm{NaOH}$ did not perform well in column mode with the HW simulant. Table 4 lists the ratio of concentration of Cs-137 found in column effluents relative to the influent concentration at various flow rates. The breakthrough curves are represented graphically in Figure 1.

Table 4. Breakthrough Curve Data - 2M NaOH Pretreatment

\section{Column}

Volumes

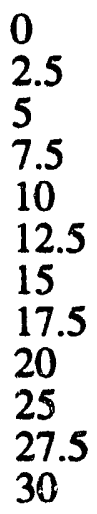

$15 \mathrm{CV} / \mathrm{hr}$

0

0

0.40

0.56

0.71

0.80

0.74

0.90

0.85

0.80
$10 \mathrm{CV} / \mathrm{hr}$

0

0

0

0.28

0.37

0.46

0.36

0.53

0.61

0.64
$7.5 \mathrm{CV} / \mathrm{hr}$

0

0

0

0.32

0.26

0.29

0.55

0.52

0.53

0.51
$3 \mathrm{CV} / \mathrm{hr}$

0

0

0

0

0

0

0

0.29

0.35

0.45

0.43 


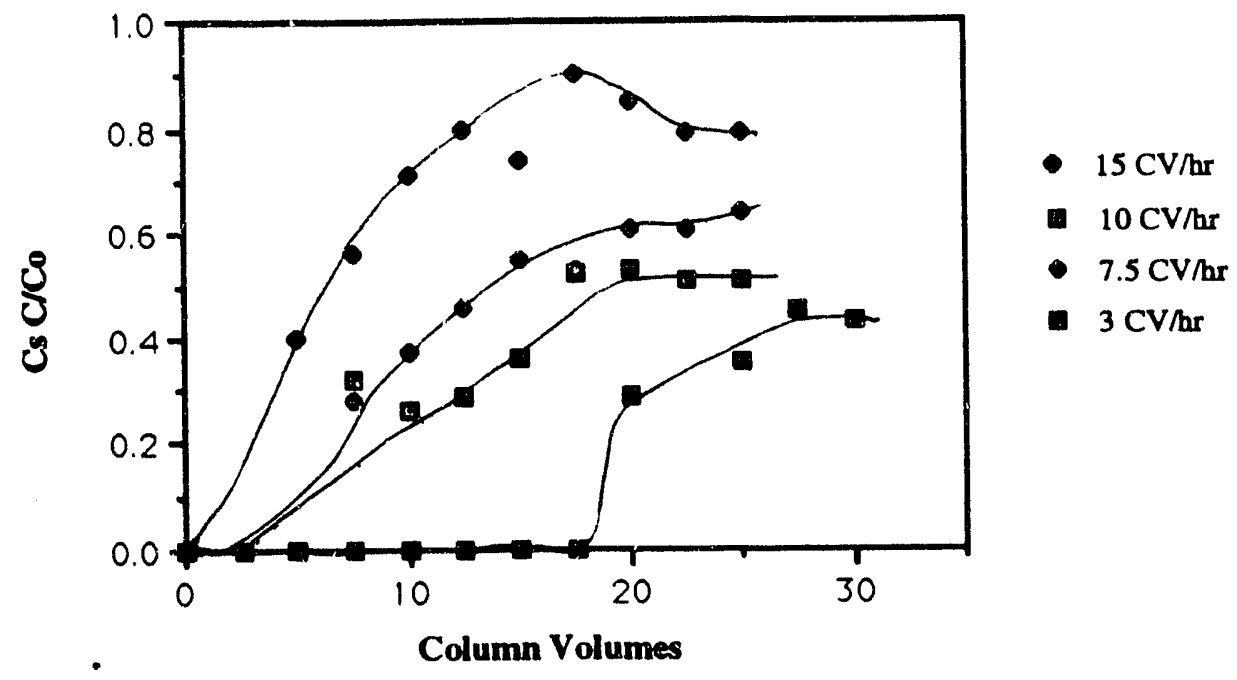

Figure 1. Breakthrough Curves for Four Flow Rates After $2 \mathrm{M}$ NaOH Pretreatment

Data for the breakthrough curve(s) generated by treating $\mathrm{HW}$ at $23^{\circ} \mathrm{C}$ at 5 column volumes per hour in a downflow mode on $0.72 \mathrm{~g}(2.18 \mathrm{~mL}$ of fully swollen resin) of the sodium form of the resorcinol/formaldehyde resin are found in Table 5. A graph of selected data is shown in Figure 2. As noted earlier, the column was allowed to idle in contact with the feed for several, long intervals during the run. The net effect of this was to establish a new equilibrium for the column, resulting in a lowering of the breakthrough curve after each shutdown. A saw-tooth pattern was generated in the breakthrough curve and those irregularities were smoothed in Figure 2 by using selected data points.

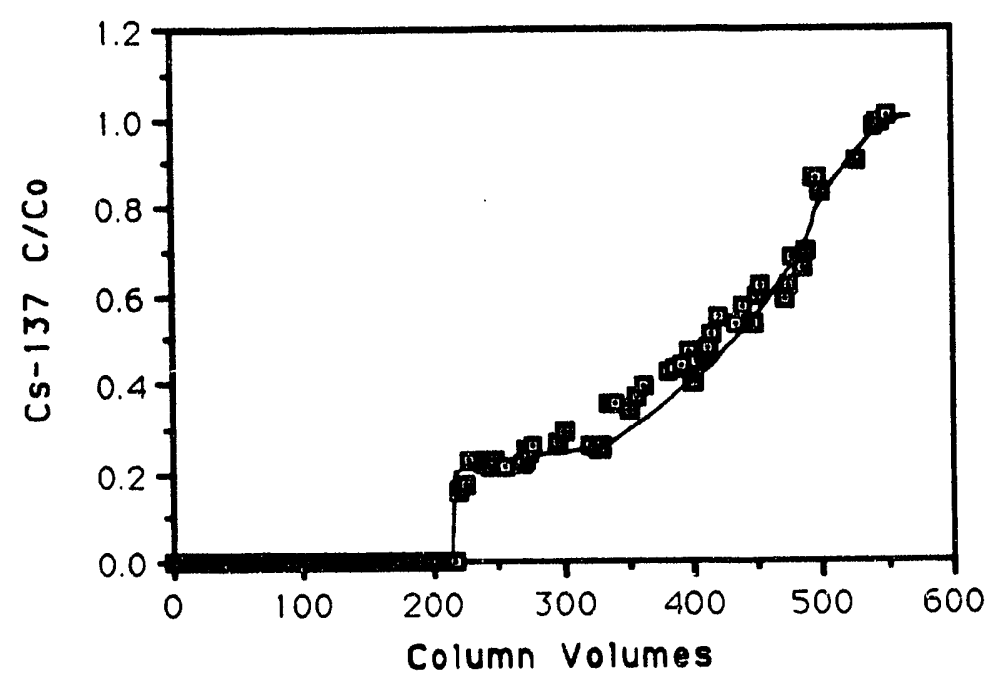

Figure 2 Breakthrough Curve at $5 \mathrm{CV} / \mathrm{hr}$ After $6 \mathrm{M} \mathrm{NaOH}$ Pretreatment 


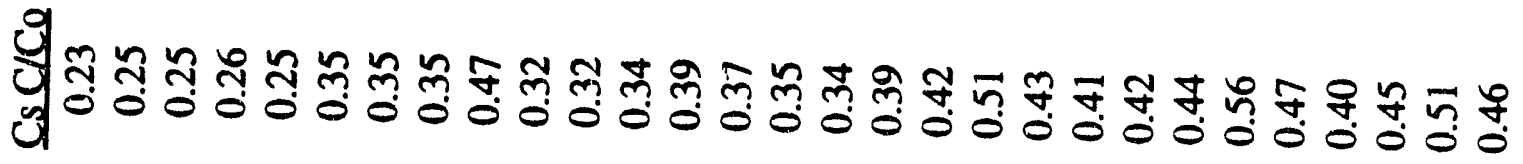

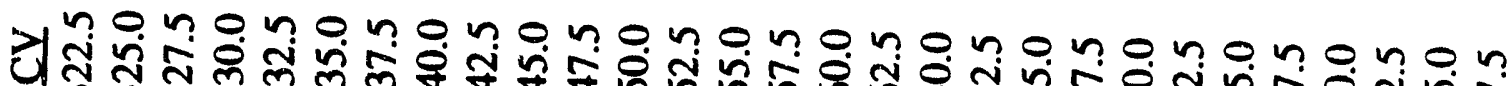

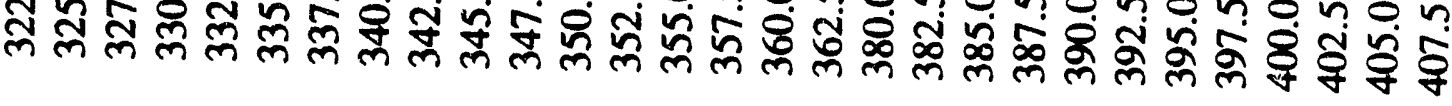

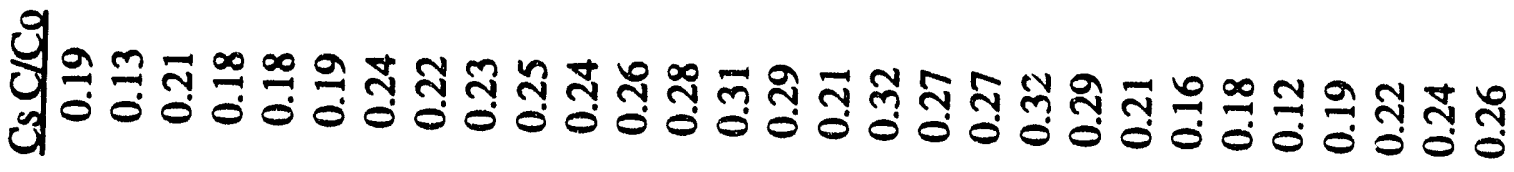

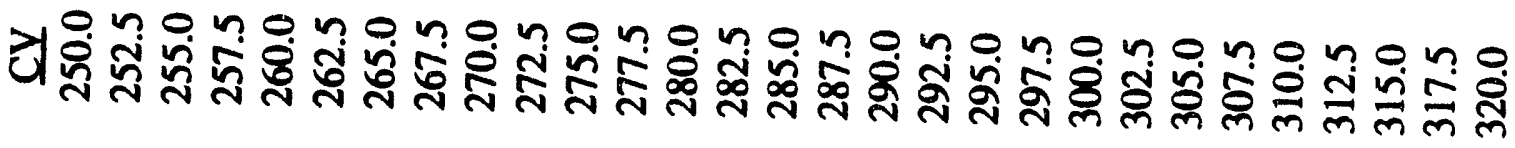

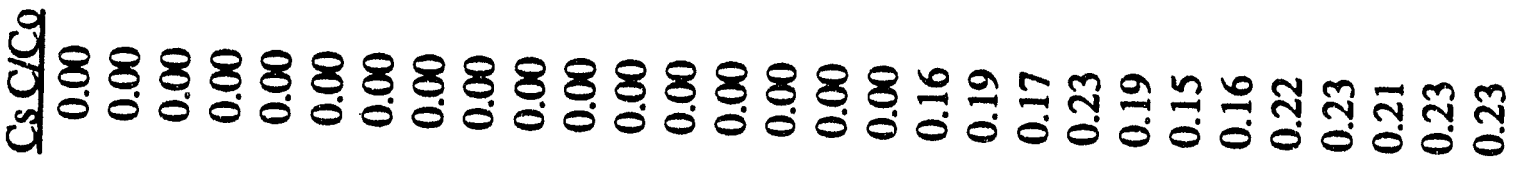

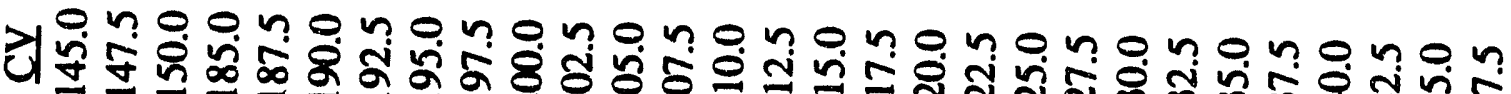

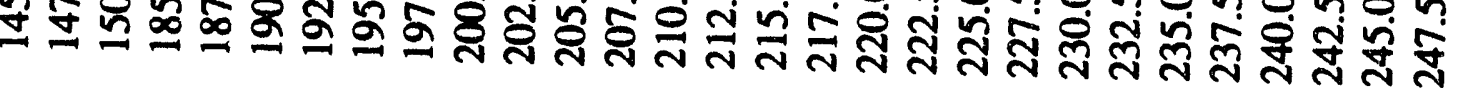

\%

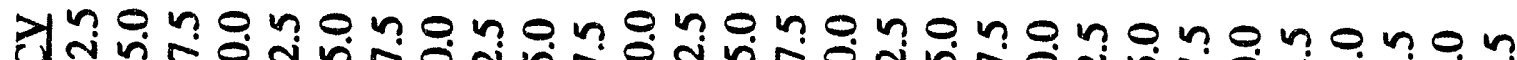
충ำ

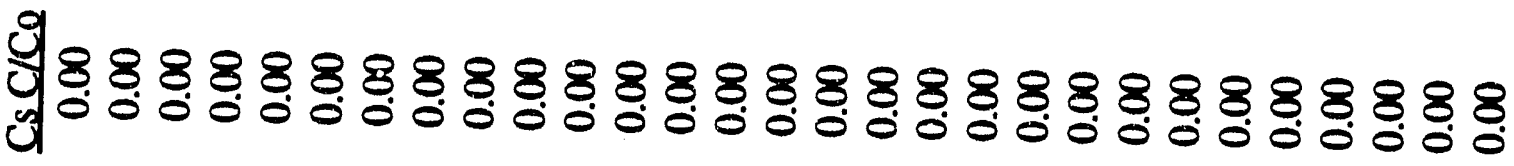

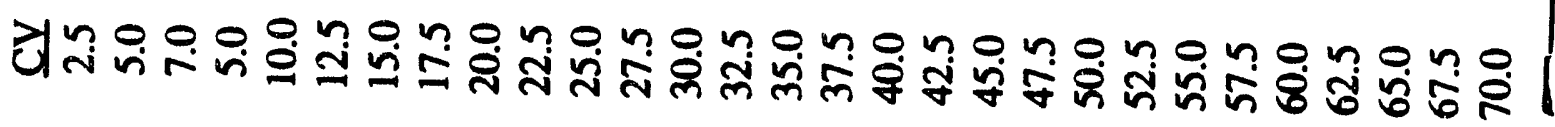


As determined from Table 5, the fraction of Cs-137 fed to the column that was actually loaded was $0.761([3.30 \mathrm{E}-1 \mu \mathrm{Ci}-7.89 \mathrm{E}-2 \mu \mathrm{Ci}] / 3.30 \mathrm{E}-1 \mu \mathrm{Ci})$. The resin column, then sorbed a total of

$$
\begin{gathered}
0.761 *(4.4 \mathrm{E}-5 \mathrm{moles} / \mathrm{L}) *(1.1 \mathrm{~L}) *(135 \mathrm{gCs} / \mathrm{mole}) *(1 \mathrm{E}+3 \mathrm{mg} / \mathrm{g}) *(1 \mathrm{CV} \text { resin } / 0.72 \mathrm{~g})= \\
6.9 \mathrm{mg} \mathrm{Cs} / \mathrm{g} \text { resin or } 5.1 \mathrm{E}-2 \text { milliequivalents } \mathrm{Cs} / \mathrm{g} \text { resin. }
\end{gathered}
$$

Pretreating the column with a strong enough caustic solution that will allow the resin to swell as much as it does in the feed allows the column to operate effectively for ion exchange. Earlier premature breakthrough curves may have been the result of channeling while the resin continued to swell in the early stage of column feeding. It might also have resulted from microscopic precipitation of aluminum on the resin, a process that would ultimately blind the column to ion exchange. This is the first test in which the second hydroxide moiety has been active. Previous work with WSRC and Hanford NCAW (Neutralized Current Acid Waste) and CC wastes had only observed one breakthrough for those feeds, all of which are only between 1 and 2 molar in free hydroxide. The net effect of the activation of the second hydroxide is to increase the capacity of the resin. This flow rate, 5 column volumes per hour, gave a very sharp initial breakthrough, indicating that a more rapid flow rate could be accommodated if desired.

Based on these observations, the resin should be pretreated with a solution that closely resembles the expected feed to minimize swelling or shrinking of the resin in the column after the feed cycle begins.

\subsection{Elution}

The elution of the column that had been pretreated with $6 \mathrm{M} \mathrm{NaOH}$ was accomplished in an upflow mode with $0.1 \mathrm{M} \mathrm{HNO}_{3}$ after washing the resin with $100 \mathrm{~mL}$ of deionized water to remove any interstitial supernate. Table 6 shows the eluate concentrations of Cs137 and potassium ion. Sodium analyses are not complete. Data is presented graphically in Figures 3 and 4 . The eluted amount of $\mathrm{Cs}-137(0.252 \mu \mathrm{Ci})$ is equal to the calculated amount of $\mathrm{Cs}-137$ sorbed hy the column $(0.251 \mu \mathrm{Ci})$. Potassium ion that was eluted from the resin surprisingly showed two elution peaks. Potassium ion began eluting from the column before cesium ion. Essentially all of the cesium and potassium ions was eluted in 47.5 column volumes of $0.1 \mathrm{M} \mathrm{HNO} 3$. 


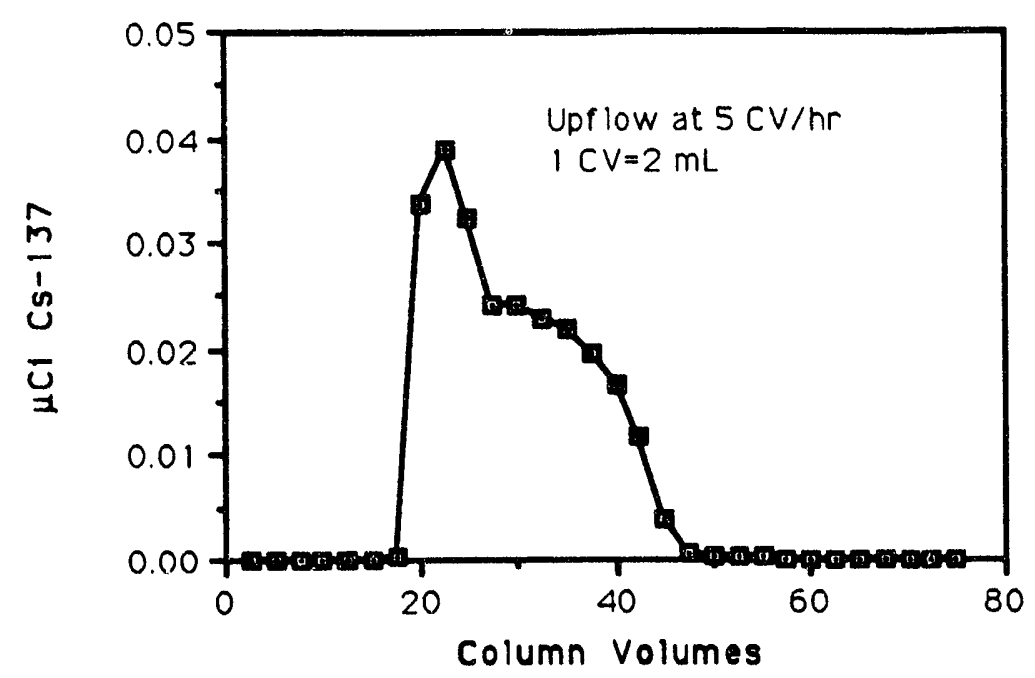

Figure 3. Elution of $\mathrm{Cs}^{+}$With $0.1 \mathrm{MHNO3}$

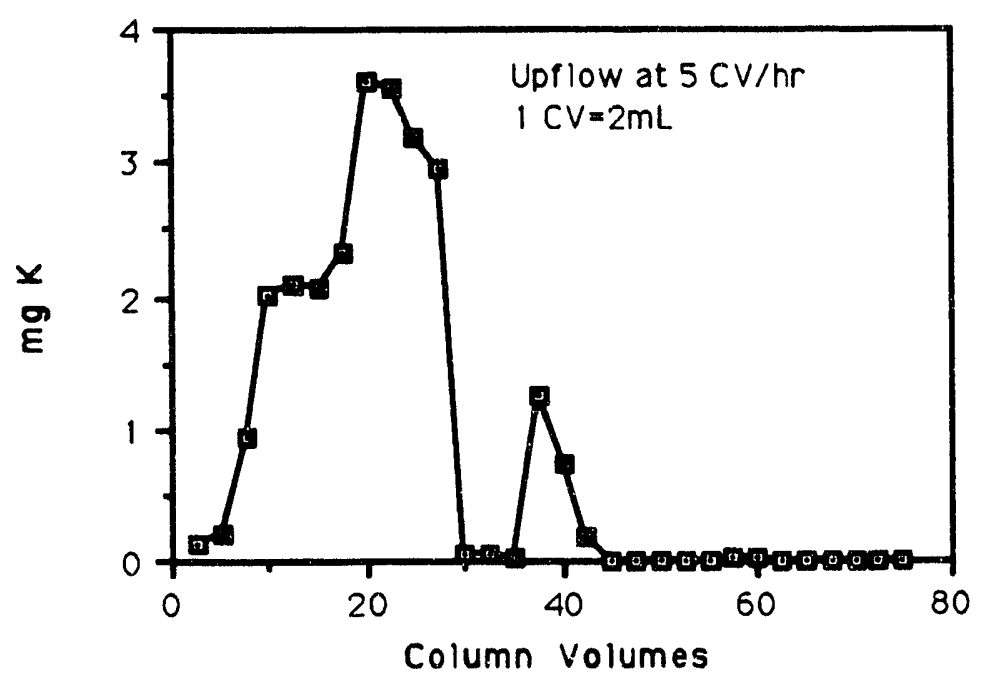

Figure 4. Elution of $\mathrm{K}^{+}$With $0.1 \mathrm{M} \mathrm{HNO}_{3}$ 
S.D. FINK

Table 6 Concentrations of Ions in $0.1 \mathrm{M} \mathrm{HNO}_{3}$ Eluate

$\mathrm{CV}(1 \mathrm{CV}=2 \mathrm{~mL})$

2.5

5.0

7.5

10

12.5

15

17.5

20

22.5

25

27.5

30

32.5

35

37.5

40

42.5

45

47.5

50

52.5

55

57.5

60

62.5

65

67.5

70

72.5

65


0

0

0

0

0

0

0

0.034

0.039

0.032

0.024

0.024

0.023

0.022

0.020

0.017

0.012

0.004

0.001

0

0

0

0

0

0

0

0

0

0

0

Total $\quad 0.252$
WSRC-RP-93-610

April 29, 1993

Page 11 mg K

0.130

0.205

0.935

2.03

2.09

2.08

2.32

3.60

3.57

3.20

2.95

0.050

0.045

0.035

1.23

0.720

0.175

0.005

0.010

0.005

0.005

0.005

0.015

0.015

0.005

0.005

0.005

0.005

0.005

0.005

25.8

\subsection{Shelf-life Related Studies}

\subsubsection{Kd Tests After Five Years In Storage}

Batch distribution coefficients determined on grab samples of resin from drums that were received at WSRC in 1988 are compared with those determined for resin grab samples tested with solutions of the same composition when the resin was ne".iy received. Resin 
from four drums was tested. These results appear graphically in Figure 5 and in tabular form in Table 7. They represent Kd's determined using solution number 2 (see Table 2).

These results, also experienced by researchers dealing with the resin at PNL and Oak Ridge, indicate that the resin degrades with time. It was not tested for several years and, during that time, appeared to retain its high selectivity for cesium ion. Exposing the resin to the atmosphere appears to cause it to degrade. The me chanism for that reaction is not known. Elucidation of the mechanism would give insight into the proper storage conditions for the resin to prevent its degradation.

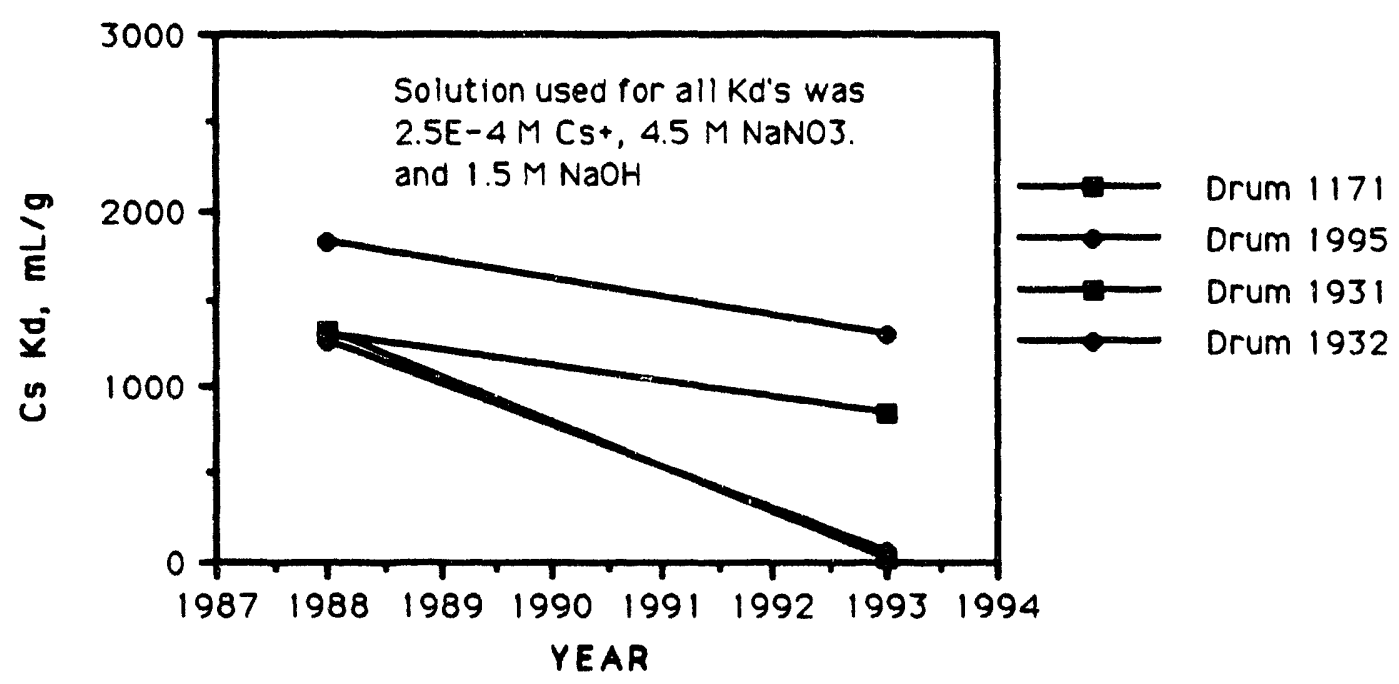

Figure 5. Loss in Kd by Resin with Time

Table 7. Cs Kd's for Resin From Four Drums * A Five Year Time Difference

Drum\#

1171

1995

1931

1932

1989 Cs Kd. mL/g
1993

$8.51 \mathrm{E}+2$

$6.86 \mathrm{E}+1$

$1.36 \mathrm{E}+1$

$1.30 \mathrm{E}+3$

\subsubsection{Effect of Ereezing on Cs Kd}

The $\mathrm{Kd}$ values that were determined for resin grab samples from the same four drums as noted in 4.3.1 after three, three-day freezing and thawing cycles, are reported in Table 8. These Kd's were determined by allowing the resin to equilibrate with solution number 2 , Table 2. All four solutions described in Table 2 were used to determine Cs Kd values, but data from those tests is not reported because it was derived from $\gamma$-counting shortly 
S.D. FINK

WSRC-RP-93-610

April 29, 1993

Page 13

after the counter had been struck by lightning and results are suspect. Data in Table 8 was determined after the instrument had been repaired.

Repetitive freezing and thawing cycles do not have any significant effect on the performance of the resin.

Table 8. $\mathrm{Cs}^{+} \mathrm{Kd}$ 's Determined After Three Freezing/Thawing Cycles

Cs Kd's

\begin{tabular}{cllll} 
\# Ereeze/Thaw Cycles & Drum 1771 & Drum 1995 & Drum 1931 & Drum 1932 \\
\cline { 2 - 3 } 0, untreated & $8.51 \mathrm{E}+2$ & $6.86 \mathrm{E}+2$ & $1.36 \mathrm{E}+1$ & $1.30 \mathrm{E}+3$ \\
1 & $7.89 \mathrm{E}+2$ & $6.45 \mathrm{E}+1$ & $1.61 \mathrm{E}+1$ & $1.22 \mathrm{E}+3$ \\
2 & $9.18 \mathrm{E}+2$ & $2.97 \mathrm{E}+1$ & $6.52 \mathrm{E}+1$ & $1.61 \mathrm{E}+3$ \\
3 & $9.67 \mathrm{E}+2$ & $5.55 \mathrm{E}+1$ & $2.36 \mathrm{E}+1$ & $1.45 \mathrm{E}+3$
\end{tabular}

The data is shown in graphic form in Figure 6.

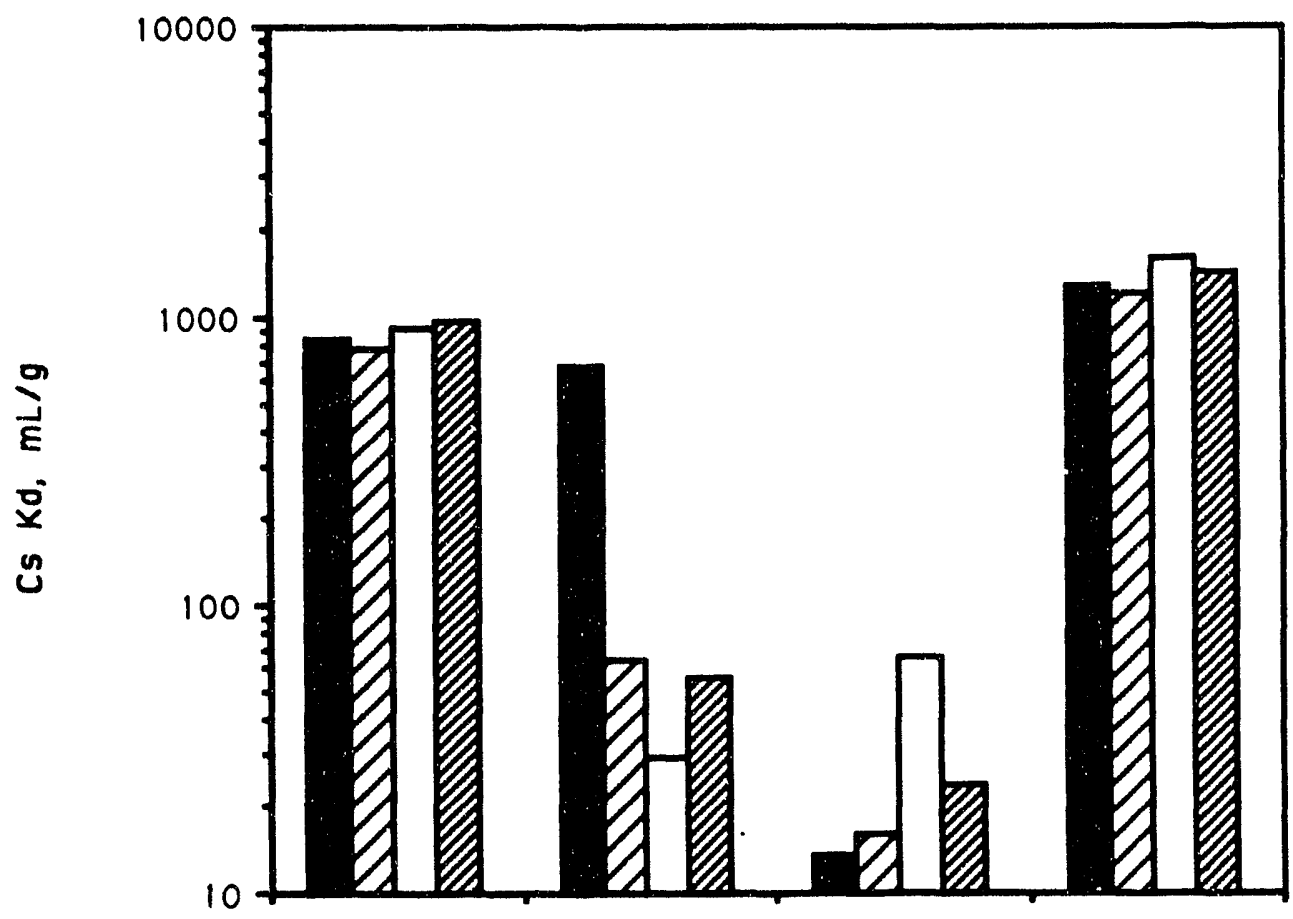

Untreated

Freeze

Freeze 2

Freeze 3

Figure 6 . The Erfect of Repeated Freezing and Thawing on $\mathrm{Cs}^{+} \mathrm{Kd}$ 


\subsubsection{Exposure of Resin to Air}

Cesium Kd's were performed on samples of Drum 1995 resin that had been exposed to 90 psig compressed air for one week. These are contrasted with the $\mathrm{Cs}^{+} \mathrm{Kd}^{\prime}$ for the same resin that had not been treated with air. The data is presented graphically in Figure 7.

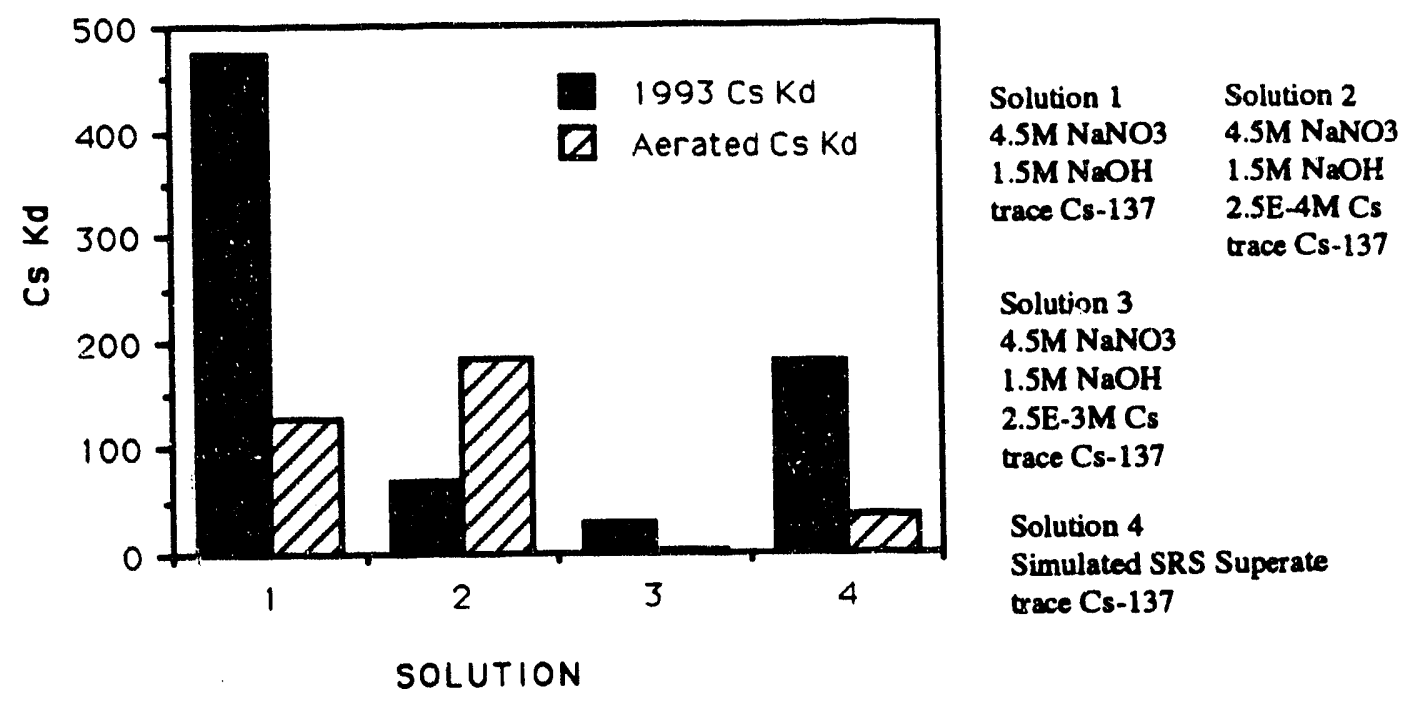

\section{Figure 7. The Effect on $\mathrm{Cs}^{+} \mathrm{K}$ after Exposure of the Resin to Air}

Air, either oxygen or ozone or both, appears to cause the resin to degrade and lose its specificity and capacity for cesium. Studies on the mechanism of degradation have not been made at this time.

\subsection{Radiolysis Results and Discussion (Contributed by N.E. Bibler and C.L. Crawford)}

\subsubsection{Visual Observations}

The resin swelled upon the addition of simulated supernate or water. The unirradiated resin in presence of both supernate and water swelled by $15 \%(2.0 \mathrm{~mL}$ to $2.3 \mathrm{~mL})$. Radiolysis slightly enhanced the swelling. With the irradiation, the resin swelled by values ranging from $20 \%$ to $30 \%(2.0$ t0 $2.6 \mathrm{~mL})$. There was no consistent trend of swelling with radiation dose, and the resin swelled similarly in water or supernate. Radiation-induced volume changes have been observed with this and other resins. $3,4,5$

When either the supernate, which was originally light yellow, or deionized water was added to the resin, the solutions became brownish. It has been suggested that this brownish color resulted from leaching of the resin in caustic solutions. 3 When the resinsupernate samples were irradiated the brownish color was enhanced. When resin-water samples were irradiated, radiolysis caused the supernate to become colorless. In this case 
it appears that radiolysis destroyed the species that were causing the color. HPLC will be used in an attempt to identify the species causing the color.

One other visual observation was noted. After the resin-supernate samples were irradiated, a small amount of white solids was visible on the resin. These solids did not form when the resin-water samples were irradiated. Also, they did not appear in any of the unirradiated samples. Since the resin-supernate samples were highly caustic, it was speculated that radiolysis may initiate dissolution of the glass tube. The tubes were emptied, dried and reweighed. Those tubes in which the resin-supernate were irradiated actually lost weight, albeit a very small amount. Perhaps this result is due to the radiation- enhanced caustic dissolution of glass. The solids will be analyzed for $\mathrm{Si}$ to determine if this is indeed the case. The possibility of performing the resin-supernate irradiations in stainless steel vessels is being investigated.

\subsection{2 $\mathrm{pH}$ Measurements}

The $\mathrm{pH}$ values for the resin-water samples are shown as a function of dose in Table 9. The supernate was already highly caustic, thus its $\mathrm{pH}$ could not be measured accurately. The initial $\mathrm{pH}$ of the water was in the range of 6 to 7 . (Exact $\mathrm{pH}$ measurements of completely deionized water are difficult because the water is not poised and rapidly sorbs $\mathrm{CO}_{2}$ from the air.) After the deionized water was added to the resin, the $\mathrm{pH}$ increased to 10.4. The initial $\mathrm{pH}$ increase may be due to washirg residual $\mathrm{KOH}$ from the resin. $\mathrm{KOH}$ is used in the synthesis of the resin. As seen in Table 9, radiolysis caused the $\mathrm{pH}$ to decrease in a consistent manner with dose, suggesting the formation of soluble organic acids. Acids resulting from the radiolysis of a resorcinol-type structure could be substitutéd phenols. This will be investigated by submitting samples for HPLC for soluble organic species.

TABLE 9. pH Changes Caused by Radiolysis of Resin-Water Mixtures

$\begin{array}{cr}\mathrm{DOSE}(\mathrm{rad}) & \mathrm{pH} \\ 0 & 10.48 \\ 1.6 \mathrm{E} 08 & 9.82 \\ 3.7 \mathrm{E} 08 & 9.73 \\ 5.4 \mathrm{E} 08 & 9.63\end{array}$

\subsubsection{Effect of Radiation on the Kd Values}

$\mathrm{Kd}$ values were measured on the irradiated and unirradiated samples. When duplicate values were measured, the precision was poor especially with the resin-supernate samples. For example, for two different unirradiated resin-supernate samples and for two different resin-supernate samples irradiated to the highest dose, the results varied by a factor of $2 \mathrm{X}$. Consequently, the Kd results for the resin-supernate samples were too imprecise to evaluate the effect of radiation on Kd. There are two possible sources of the imprecision. One was the drying of the resin after it was irradiated. The resin-supernate samples were dried using two different techniques. As a result, varying amounts of water remained in the resin samples. Since the Kd values are based on resin weight, this caused 
the results to be imprecise. Second, the white solids, if they were formed by dissolution of a portion of the glass irradiation vessel, would add varying amounts to the weight of the resin samples and would also increase the imprecision of the results. The resins from the resin-water irradiation were all dried by the same method (air dried for one hour at room temperature). As mentioned before, these samples contained no white solids. Consequently, the $\mathrm{Kd}$ values for these samples were more precise (relative precisions of 4 and $22 \%$ were obtained for the two sets of duplicate samples). The Kd values shown in Table 10 were measured in four different solutions. The compositions of these solutions were given earlier in Table 2.

TABLE 10. Effect of Gamma Radiation on $\mathrm{Kd}(\mathrm{mL} / \mathrm{g})^{\mathbf{a}}$

SOLUTION NUMBER

\section{DOSErads}

3

$26 \pm 3$

$(1.6 \pm 0.3) \mathrm{E}+2$

$1.6 \mathrm{E}+2$

$0.68 \mathrm{E}+2$

$1.6 \mathrm{E}+8$

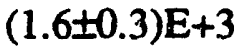

$3.7 \mathrm{E}+8$

$1.7 \mathrm{E}+3$

$5.4 \mathrm{E}+8$

(2.4 \pm 0.4$) \mathrm{E}+2$
25

21

$27 \pm 0.2$
SS

$(1.8 \pm 0.4) \mathrm{E}+2$

$1.2 \mathrm{E}+2$

$2.0 \mathrm{E}+2$

(2.7 \pm 0.1$) \mathrm{E}+2$

a Resin samples dried for one hour.

The Kd values in Table 10 are nominally an order of magnitude less than those previously reported.6,7 Again, this is due to different drying techniques. The samples used in the previous reports were air dried overnight and those used to generate the data in Table 10 were air dried for only one hour. The presence of larger amounts of water in the resin samples would lower the $\mathrm{Kd}$ value. Subsequent drying at $100^{\circ} \mathrm{C}$ of the samples used for the data in Table 10 indicated that they contained nominally $70 \%$ water. Those air-dried overnight contained less than $30 \%$ water. $^{3}$

Even though the $\mathrm{Kd}$ values in Table 10 are lower than those reported previously, the values do show the same trend with Cs concentration as that reported previously. 6 The data in Table 10 indicate that, with an increasing Cs concentration (solutions 1, 2, and 3), the $\mathrm{Kd}$ values decrease. This decrease is consistent with results from a previous study. 6 The results in that study also indicate that when the solutions have similar Cs concentrations, the Kd values should be similar. Solutions 2 and 4 have the same Cs concentration $(2.5 \mathrm{E}-4 \mathrm{M})$ and indeed their $\mathrm{Kd}$ 's are similar. Thus the values in Table 10 are valid even though the resins were dried only one hour.

The $\mathrm{Kd}$ values in Table 10 are not very precise, but they do indicate that there is not a significant effect of radiation on the Kd of the resin when it is irradiated in water to a dose of $5.4 \mathrm{E}+8$ rads. Other studies have shown that when the resin is irradiated in caustic nitrate solutions simulating high-level waste solutions, radiation causes the $\mathrm{Kd}$ to decrease. For example, a dose of $1.4 \mathrm{E}+8 \mathrm{rads}$ lowered the $\mathrm{Kd}$ by $98 \% .7$ In another study 6 , a dose of $1 \mathrm{E}+9$ rads lowered the $\mathrm{Kd}$ by $82 \%$ while a dose $9 \mathrm{E}+7$ did not lower it. It may be that in water the resin is stable to attack by intermediates formed by the 
radiation, but this is highly unlikely since the resin does radiolytically decompose in caustic solution. However, it is evident that $\mathrm{Kd}$ values are not a sensitive measure of the radiation stability of a resin. Future tests will be performed to determine if indeed the resin is stable when irradiated in water.

\subsection{Future Work}

Column studies continue in order to optimize the flow rate. Viscosity studies are underway to study the effect of temperature on the viscosity of $\mathrm{HW}$. Sodium data for the elution will be soon complete. Elution at different flow rates will be performed to optimize that process. Operation of a small column at temperatures between $40^{\circ} \mathrm{C}$ and $80^{\circ} \mathrm{C}$ will be completed. Further analyses of irradiated solutions will continue. In particular, simulated supernate and water solutions above irradiated samples will be analyzed by HPLC for soluble organic compounds, especially compounds such as nitrated organics which might represent an explosion hazard. The solutions from the resin-water samples will be analyzed by ion chromatography for soluble organic anions that may have been formed. These resin-water supernates will also be analyzed to determine concentrations of sodium and potassium ion that would become solubilized as the resin degrades. A major effort of the immediate radiolysis studies will be to determine the effect of radiation on the resin when it is irradiated in the presence of HW. This will require a refining of the determination of the $\mathrm{Kd}$ values, a refining of the measurement of weight loss induced by radiation, and determining the best analyses of solutions irradiated with resin.

\subsection{BUDGET AND SCHEDULE}

Funding for this work was received from the Office of Technology Development in January. Early estimates for a spendout rate of $\$ 30,000$ per month for January, February, and March somewhat exceed the $\$ 69,000$ that has been actually been spent to date. It should be noted that $\$ 25,520$ of analytical costs for those months was incorrectly charged against a Waste Management activity code. That error was corrected and the analytical costs have been assigned to this project. Although the scope of this work has broadened due to the issue of the resin's shelf life, the originally planned tasks are proceeding as proposed in the original schedule.

\subsection{QUALITY ASSURANCE}

Data for this work can be found in notebooks WSRC-NB-90-188 and DPSTN-4268. Reagent grade chemicals were used for all solutions. Standards used in analyses are traceable to the National Institute of Standards and Testing. These were performed by the WSRC Analytical Development Section following that section's procedures for customer assisted analysis, using blanks and standards.

\subsection{REFERENCES}

1. N. E. Bibler, "Calibration of Intense Co-60 Sources at the Savannah River Plant", US ERDA Report DP-1414, May, 1976.

2. H. Fricke and E. J. Hart, "Radiation Dosimetry, Vol. 2 (2nd ed.) F. H. Attix and W. C. Roesch, editors, Academic Press, p. 85 (1966). 
3. J. P. Bibler, Savannah River Technology Center, Westinghouse Savannah River Co., Aiken, SC; private communication.

4. S. F. Marsh, "The Effects of Ionizing Radiation on Reillex HPQ, A New Macroporous Polyvinylpyridine Resin and on Four Conventional Polystyrene Anion Exchange Resins,", Los Alamos National Laboratory report LA-11912 (November 1990).

5. E. W. Baumann, "Gamma Irradiation of Individual and Mixed Ion Exchange Resins", J. Chem. Eng. Data., Vol 11, 256 (1966).

6. J. P. Bibler,, "A Comparison of Duolite CS-100 and Resorcinol/Formaldehyde Ion Exchange Resins with Three High-Level Waste Simulants Before and After Gamma Radiation", WSRC-RP-91-1221, December 11, 1991.

7. J. P. Bibler, R. M. Wallace, and L. A. Bray, "Testing a New Cesium-Specific Ion Exchange Resin for Decontamination of Alkaline High-Activity Waste", Proceedings of Waste Management ' 90 , Vol. 2, pp. 747-757.

CC: W.L. Tamosaitis, 773-A

N.E. Bibler, 773-A

C.L. Crawford, 773-A

B.G. Kitchen, 773-41A (5)

M.J. Plodinec, 773-A

CHC file, 773-A

SRTC Records (4) 

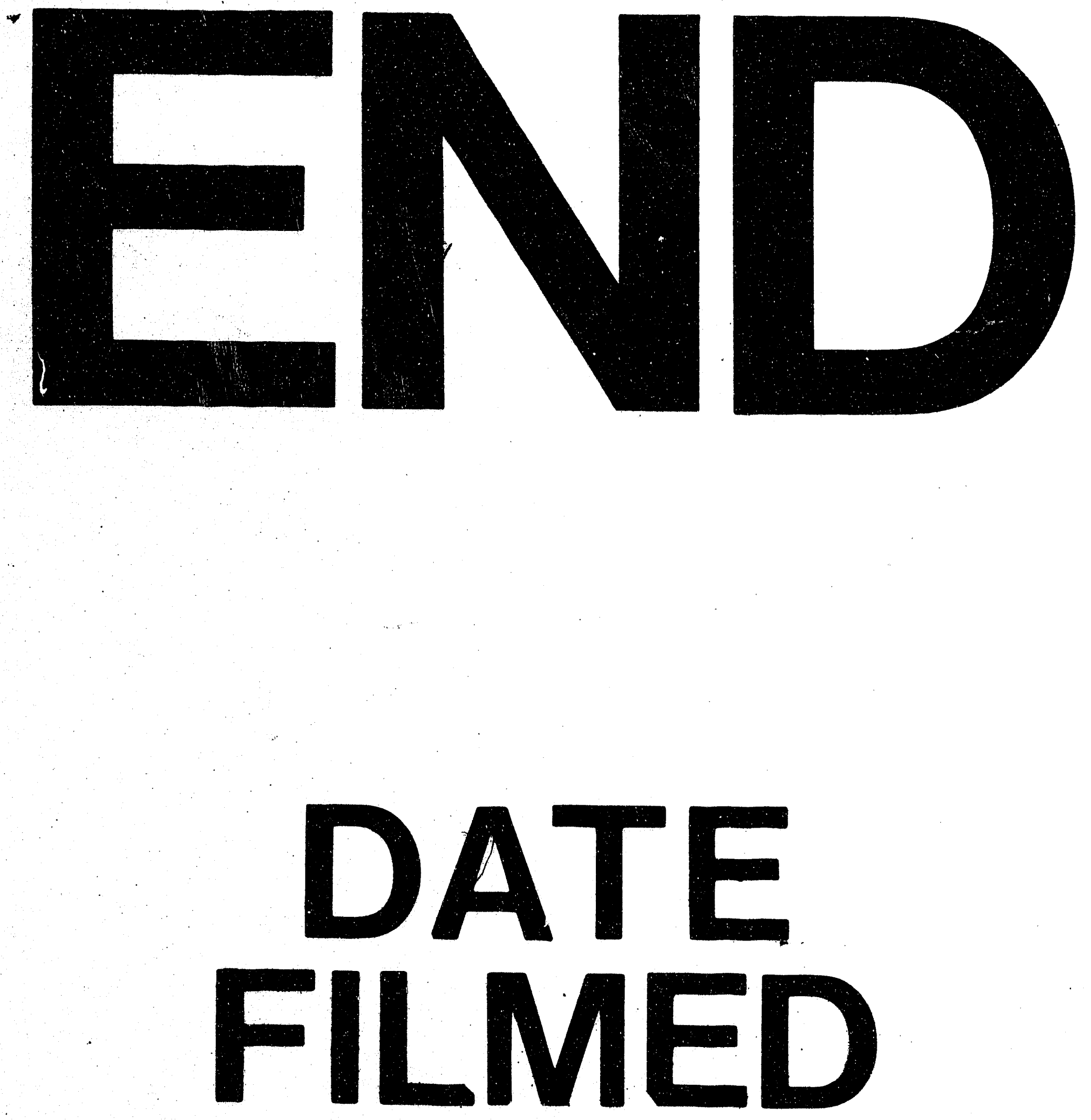

1.

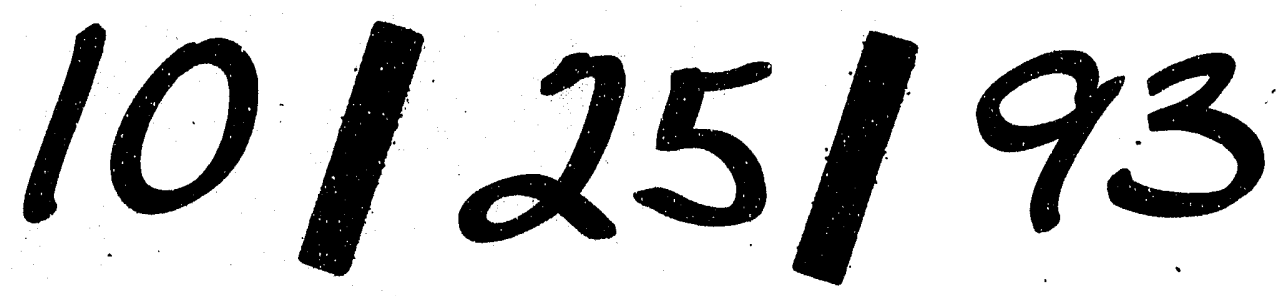


